\title{
Aflatoxin B1 contamination in sunflower oil collected from sunflower oil refinery situated in Karnataka
}

\author{
Narasimhan Banu ${ }^{1 *}$, JohnPaul Muthumary ${ }^{2}$ \\ ${ }^{1}$ Department of Biotechnology, Vels University, Chennai, India; *Corresponding Author: banunk1@yahoo.com, \\ banu sivakumar@rediffmail.com \\ ${ }^{2}$ Centre for Advanced Studies in Botany, University of Madras, Chennai, India
}

Received 11 March 2010; revised 15 April 2010; accepted 17 April 2010.

\begin{abstract}
In the present study, the aflatoxin B1 contamination at various stages of oil refining and in refined oil were carried out. This was subsequently compared with commercial vegetable oil samples. Among the $\mathbf{2 3}$ different sunflower oil samples were tested, 10 of them showed positive results to $A F B 1$ and the remaining 13 showed negative results to AFB1. All the refined oil samples were free from AFB1 contamination.
\end{abstract}

Keywords: Aflatoxin B1; Refined Oil; Raw Oil; Filtered Oil; Sunflower Oil; Edible Oil

\section{INTRODUCTION}

Fats and oils are an essential part of our diet, supplying nutrients, improving flavor, aiding in the absorption of vitamins, and providing concentrated sources of energy for our body. Food fats and oils are derived from oilseed and animal sources. There is an universal demand for vegetable oil due to its use in domestic cooking, as an ingredient for other food production (in baked goods and fried snack foods), and as a raw material for the manufacture of soap, body/hair oils and detergents. Oils and fats are natural products and that consequently the impurity levels will vary not only with oil type but also with weather, soil, harvesting, feed, storage and extraction conditions [1]. Sunflower oil is the preferred oil in most of Europe, East Europe, Russia, Mexico, countries along with Mediterranean and several South American countries.

Oil processing involves three major conventional processes which include continuous neutralizing, bleaching and deodourisation. Neutralisation of crude oil with caustic soda is still an essential feature for a refinery required to produce a consistently high quality product and to handle a number of different oil types. Strong caustic soda solutions $(4 \mathrm{~N})$ when mixed with oil will saponify triglycerides, with consequent increase in neutral oil loss, but this loss can be minimized by suitable conditions, and concurrent saponification of pigments with removal via the soap stock is a valuable way of recovering poorer quality oil. A bleaching step is necessary to remove soap, trace metals, sulphurous compounds and part of the more stable pigments and pigment break-down products which have resulted from raw materials damage or oxidation. During the bleaching stage, peroxides are broken down to aldehydes and ketones and these secondary oxidation products are adsorbed on the earth surface such that the filtered oil after bleaching should have Peroxide Value (PV) of nil. The deodorization process, involves steam distillation under vacuum. Its purpose is to remove, so far as possible, residual free fatty acids, aldehydes and ketones which are responsible for unacceptable oil odours and flavors and, more recently to decolourise the oil by heat decomposition $\left(270^{\circ} \mathrm{C}\right)$ of the pigments, and distillation of the decomposition products [1]. Traces of aflatoxins ranging from 3 to $16 \mu \mathrm{g} / \mathrm{Kg}$ in 13 of 28 samples of crude peanut oil imported to Malaya from Hong Kong and Singapore $[2,3]$. They did not detect any aflatoxins in five samples of refined peanut oil produced by laboratory refining of crude oils which had been found to be contaminated.

Aflatoxin contamination in crude oils extracted from the seeds has been reported in groundnut [4]. On studying the state of aflatoxin in raw peanut oil it was found that $65-70 \%$ present in the sediment and $30-35 \%$ in the supernatant oil on centrifugation indicating that the toxin is sparingly soluble in oil [5]. Mixing of 2\% Fuller's earth with raw oil and centrifuging resulted in adsorption of toxin to the earth material thereby the clear oil contained only $10-15 \%$ of what was originally present. Based on these data, filter pads to suit plate-and-frame filter press in pilot plant/oil mills are prepared and aflatoxin could be removed successfully to the extent of $85 \%$ on filtration $[6,7]$. Low levels of aflatoxin in oils, except for unrefined peanut oil in India [8]. 
A simple method was proposed for aflatoxin determination in vegetable oils [9]. The method was successfully applied to both crude and degummed oils. The oils analysed contained aflatoxin B1 at levels of 5-200 $\mu \mathrm{g} / \mathrm{Kg}$. Recoveries of AFB1 standards added to aflatoxin-free oils were between 89.5 and $93.5 \%$, with coefficients of variation of $6.3-8.0 \%$. During 1984-1985, 60 samples (corn, peanut, cottonseed, olive, safflower, salad, walnuts and sesame seed oil) were analysed for aflatoxins, trichothecenes and zearelenone. Aflatoxins were detected in 5 of 8 samples of peanut oil (aflatoxin B1 0.52$0.72 \mathrm{ppb}, \mathrm{B} 2$ 0.09-0.22 ppb, G1 0.07-0.08 ppb and G2 $0.01 \mathrm{ppb})$. Crude oils, obtained from corn germ were spiked with aflatoxins (0.8-1.0 ppm), deoxynivalenol (8 $\mathrm{ppm}) /$ nivalenol (8 ppm) and zearelenones (10 ppm), and then refined by stimulated commercial procedure. No detectable mycotoxins remained in the edible oil. In particular, neutralization process, including alkaline refining and washing and decolorizing processes, eliminated mycotoxins [10].

Proper storage of vegetable oil has a shelf life ranging from 6-12 months. Heat applied during processing destroys enzymes in raw materials, and also any contaminating microorganisms, which would cause rancidity. Additionally, the oil may be heated after extraction to remove as much water as possible; this lessens the occurrence of microbial spoilage during storage. Correct packaging and storage conditions slow down chemical changes caused by light and heat, which may lead to rancidity [11]. The storage of raw sunflower oil in four different packaging materials viz., plastic, tin, hindolium and high-density polyethylene (HDPE) pouches [12]. The effect of heat treatment on storability of oil under airtight and non-airtight conditions was also studied. In the case of heat treatment, the oil was heated up to $120^{\circ} \mathrm{C}$ for 90 minutes in order to inactivate the lipase enzyme completely. It was observed that during storage, different packaging materials and heat treatment affected the colour, odour, free fatty acids and iodine value of oil. The airtight HDPE pouches (120 gauge) with heattreated oil were found to be the best packaging materials for storage of oil up to a period of 16 weeks.

The present study was the first report of aflatoxin B1 from sunflower oil, where the oil is being extracted.

\section{MATERIALS AND METHODS}

\subsection{Sample Collection}

\subsubsection{Sunflower oil Samples}

A total of 23 different sunflower oil samples of each
$100 \mathrm{ml}$ were collected. It includes 11 Raw oils viz., RO1a, RO1b, RO1c, RO1d; RO2a, RO2b, RO2c; RO3a, RO3b, RO3c and RO3d; 8 Filtered oils viz., FO1a, FO1b, FO1c, FO1a; FO2a, FO2b, FO2c, FO2d and 4 refined oils viz., REF3a, REF3b, REF3c and REF3d. (RO-Raw oil; FO-Filtered oil; REF-Refined oil; 1-Nayan proteins; 2-Lakshmi industries; 3-Raviprakash refinery; a-d-number of samples) The above samples were collected between 2003 and 2004 and evaluated for AFB1.

\subsubsection{Commercial Vegetable oil Samples}

One hundred mililitre of different vegetable oils like Goldwinner, Saffola, Sunland, Sundrop, Gemini, S.V.S. (Sunflower oil), V.V.S., Idaiyam, Anandam (Gingelly oil), Ruchi (Palm oil) were obtained from local markets at Chennai in pouches. Three different samples of peanut oils (unbranded) were also obtained from the local market at Chennai in sterilized vials for aflatoxin B1 evaluation.

\subsubsection{Preparation of Column (Miller et al., 1985)}

Slurry of silica gel for column chromatography (60-200 mesh) with hexane was prepared. It was tightly pack in the column $(50 \mathrm{~cm}$ height and $1.5 \mathrm{~cm}$ width). The column was washed with diethyl ether, toluene and chloroform (100: 100: 100, v/v/v).

\subsubsection{Column Chromatography}

Five milliliter of each oil sample was dissolved in hexane and mixed with silica gel (60-200 mesh). This was loaded to the column. Aflatoxin B1 in the oil samples was eluted from the column with chloroform: methanol in the ratio of 97: 3. Same procedure was followed 2 to 3 times in order to collect the complete elution of AFB1 from the samples.

\subsubsection{Quantification of AFB1 by TLC}

$5,10,20$ and $40 \mu \mathrm{l}$ of each fractions (1,2 and 3$)$ of the partially purified aflatoxinB1 were applied to pre-coated TLC plates (Merck) along with the standard AFB1.

The TLC plates were developed in a tank containing chloroform: acetone in the ratio of 88: 12, for 30 minutes. After the development, the plates were viewed under long UV light at $365 \mathrm{~nm}$. Blue-fluorescence similar to standard AFB1 indicated the presence of aflatoxin B1 in the fractions of oil collected through the column.

Quantification of AFB1 was done using long UV light by evaluating the plate itself. The following formula is used to quantify the aflatoxin B1 in the sample:

Fluorescent intensity of the standard factor $\times$ concentrated of the standard $\times$ dilution factor

Aflatoxin content $=\frac{\text { Fluorescent intensity of the sample }}{\text { Fle }}$ 


\subsection{Ultra Violet (UV) Spectroscopic Analysis}

The partially purified sample of AFB1 collected from column chromatography was analysed by UV absorption by dissolving in $100 \%$ methanol (HPLC grade) and read at $370 \mathrm{~nm}$ in a Beckman DU-40 Spectrophotometer, compared with authentic AFB1.

\subsubsection{Infra-Red (IR) Spectroscopic Analysis}

The partially purified AFB1 was mix with IR grade potassium bromide (1:10) pressed into discs under vacuum using spectra lab Pelletiser. The spectrum of the sample was recorded (500-4000 cm-1) in a Burker 17S 85 FTIR Spectroscopy and compared with authentic AFB1.

\subsubsection{Quantification of AFB1 by High-Performance Thin-Layer Chromatography (HPTLC)}

Five $\mu$ l of fractions I and II collected through the column chromatography of different samples viz., REF3a, REF3b, REF3c and REF3d were taken for HPTLC to estimate the amount of AFB1. The fractions of I and II collected from the branded sunflower oils viz., Gold winner, Saffola, Sundrop were also estimated for AFB1. The fractions of I and II were loaded onto pre-coated silica gel plate. The plate was developed in a saturated tank containing tertiary butyl methyl ether: methanol: water in a ratio of 9.6:0.3:0.1. The developing distance of the plate was up to $80 \mathrm{~mm}$. After the development the plate was scanned in a Camag TLC scanner 3 at $366 \mathrm{~nm}$. The presence of blue-fluorescence indicated the presence of AFB1 as similar to that of authentic AFB1.

\section{RESULTS AND DISCUSSION}

In the present study, it was planned to evaluate the AFB1 contamination at various stages of oil refining and in refined oil. This was subsequently compared with that of commercial vegetable oil samples. A total of 23 different samples of sunflower raw oil, filtered oil and refined oil were collected from the Nayan proteins, Lakshmi industries and Raviprakash refinery (Table 1). From the local markets of Chennai, 13 different vegetable oil samples (sunflower, gingelly, palm and peanut oil) were collected and all the oil samples were evaluated for AFB1 contamination.

A simple method of aflatoxin determination in vegetable oils was proposed by Miller et al., (1985). The method was successfully applied to both crude and degummed oils. Recoveries of AFB1 standard added to aflatoxin free oil were between 89.5 and $93.5 \%$, with coefficients of variation of $6.3-8.0 \%$.

Among the 23 different sunflower oil samples tested, 10 of them showed positive result to AFB1 and the re- maining 13 showed negative results to AFB1 (Table 2).The sample RO1a, FO1a, RO1b and FO1c collected from Nayan proteins, $\mathrm{RO} 2 \mathrm{a}, \mathrm{FO} 2 \mathrm{a}$ and $\mathrm{FO} 2 \mathrm{c}$ collected from Lakshmi industries and RO3a, RO3c, REF a, REF $\mathrm{b}, \mathrm{REF} \mathrm{c}$ and REF d collected from Raviprakash refinery free from AFB1 contamination. The samples from the same factories but at different time of collection showed minimum level of AFB1 contamination.

The level of AFB1 contamination in fraction I collected through the column of oil samples ranged from 0.08 to $0.6 \mathrm{ppm}$, in fraction II of oil samples ranged from 0.1 to $0.6 \mathrm{ppm}$, and in the fraction III of oil samples ranged from 0.04 to $0.4 \mathrm{ppm}$ quantified by TLC method. The samples RO1b and FO1b collected from the Nayan factory AFB1 contamination of $0.1 \mathrm{ppm}$ in first fraction of RO1b. But in FO1b, it was about 0.2 ppm in first fraction and $0.3 \mathrm{ppm}$ in second fraction. The sample $\mathrm{RO} 2 \mathrm{~b}$ and $\mathrm{FO} 2 \mathrm{~b}$ collected from Lakshmi industries showed the $0.3 \mathrm{ppm}$ of AFB1 in second fraction. The samples RO3b and REF3 b collected from Raviprakash refinery showed AFB1 contamination in RO3b only $(0.4$ $\mathrm{ppm}$ ). The complete conventional type of refining processes carried by this refinery removes the AFB1 from

Table 1. List of sunflower oil samples collected from the refinery.

\begin{tabular}{ccc}
\hline S.No. & Sample Name & Name of the Refinery \\
\hline 1 & RO1a & Nayan proteins \\
2 & FO1a & Nayan proteins \\
3 & RO2a & Lakshmi industries \\
4 & FO2a & Lakshmi industries \\
5 & RO3a & Raviprakash refinery \\
6 & REF3a & Raviprakash refinery \\
7 & RO1b & Nayan proteins \\
8 & FO1b & Nayan proteins \\
9 & RO2b & Lakshmi industries \\
10 & FO2b & Lakshmi industries \\
11 & RO3b & Raviprakash refinery \\
12 & REF3b & Raviprakash refinery \\
13 & RO1c & Nayan proteins \\
14 & FO1c & Nayan proteins \\
15 & RO2c & Lakshmi industries \\
16 & FO2c & Lakshmi industries \\
17 & RO3c & Raviprakash refinery \\
18 & REF3c & Raviprakash refinery \\
19 & RO1d & Nayan proteins \\
20 & FO1d & Nayan proteins \\
21 & FO2d & Lakshmi industries \\
22 & RO3d & Raviprakash refinery \\
23 & REF2d & Raviprakash refinery \\
\hline
\end{tabular}

(RO - Raw oil; FO - Filtered oil; REF - Refined oil) 
Table 2. Quantification of AFB1 content of sunflower oil samples by TLC.

\begin{tabular}{ccccc}
\hline S. & Sample & $\begin{array}{c}\text { Fraction I } \\
\text { Level of } \\
\text { NFB1 } \\
\text { (ppm) }\end{array}$ & $\begin{array}{c}\text { Fraction II } \\
\text { level of } \\
\text { AFB1 } \\
\text { (ppm) }\end{array}$ & $\begin{array}{c}\text { Fraction } \\
\text { III level of } \\
\text { AFB1 } \\
\text { (ppm) }\end{array}$ \\
\hline 1 & RO 1 a & - & - & - \\
2 & FO 1 a & - & - & - \\
3 & RO 2 a & - & - & - \\
4 & FO 2 a & - & - & - \\
5 & RO 3 a & - & - & - \\
6 & REF 3 a & - & - & - \\
7 & RO 1 b & - & 0.1 & - \\
8 & FO 1 b & 0.2 & 0.3 & - \\
9 & RO 2 b & 0.08 & 0.3 & - \\
10 & FO 2 b & 0.2 & 0.3 & 0.4 \\
11 & RO 3 b & 0.6 & 0.4 & 0.2 \\
12 & REF 3 b & - & - & - \\
13 & RO 1 c & 0.2 & - & - \\
14 & FO 1 c & - & 0.4 & - \\
15 & RO 2 c & 0.08 & 0.4 & - \\
16 & FO 2 c & - & - & - \\
17 & RO 3 c & - & - & - \\
18 & REF 3 c & - & - & - \\
19 & RO 1 d & 0.4 & 0.5 & - \\
20 & FO 1 d & 0.3 & 0.6 & - \\
21 & FO 2 d & 0.2 & 0.2 & - \\
22 & RO 3 d & 0.5 & 0.1 & - \\
23 & REF 3 d & - & - & - \\
\hline & & & & - \\
\hline
\end{tabular}

raw oil. In refined oil there was no contamination of AFB1. In the case of RO2c and FO2c, the AFB1 was detected from $\mathrm{RO} 2 \mathrm{c}$ but it was absent in $\mathrm{FO} 2 \mathrm{c}$.

The presence and absence of AFB1 was confirmed by Ultra-Violet spectrophotometry (Figures 16-36) and Infra-Red spectroscopy (Figures 37-41).

All the refined oil samples were free from AFB1 contamination (Table 3). This was supported by the absence of fungi in the refined oil samples [13]. This may be due to oil processing which includes continuous neutralization, bleaching and deodorizations. During these processes, fungal propagules are probably removed from the oils. The toxic AFB1 have been found to be heat stable up to their melting points of around $250^{\circ} \mathrm{C}$. Therefore, AFB1 was not completely destroyed by such processes, and was carried along the way from seeds to oil samples. The complete conventional processes remove these compounds from the raw oil. But the quantity of contamination is very least ranging from 0.1 to $0.4 \mathrm{ppm}$. This low level was due to extraction of oil using food grade hexane. The extraction plays a role of partially removing aflatoxin from the oil samples.
Since, the Nayan proteins and Lakshmi industry are sunflower seed crushing units, they are not having much advancement for complete oil refining. The samples of raw oil and filtered oil collected from the factories showed below minimum level of AFB1 contamination. The Raviprakash refinery is better than Nayan and Lakshmi industries with reference to conventional oil processing. In the latter, the process removes any fungal propagules and its toxins during oil processing at very high temperature of $270^{\circ} \mathrm{C}$ for 6 hours.

All the refined oil samples (both first and second fraction) analysed by HPTLC showed no contamination of AFB1 (Figures 2-9).

The other vegetable oil samples which are commercially available like sunflower (gold winner, saffola, sundrop, Gemini, S.V.S., sunland), gingelly oil (V.V.S., idaiyam, anandam), palm oil (ruchi) and peanut oils (peanut oil 1, peanut oil 2 and peanut oil 3) were also evaluated for AFB1 contamination by TLC method (Table 4).

The sunflower oil samples like gold winner, saffola, sundrop and gingelly oil-anandam showed complete absence of AFB1 contamination. The other samples (Gemini, S.V.S., sunland, V.V.S., idaiyam, ruchi, peanut oil 1, peanut oil 2 and peanut oil 3) showed contamination ranging from 0.08 to $0.504 \mathrm{ppm}$ of AFB1. The AFB1

Table 3. Quantification of AFB1 by HPTLC.

\begin{tabular}{ccc}
\hline $\begin{array}{c}\text { Sample } \\
\text { name }\end{array}$ & $\begin{array}{c}\text { Fraction I level of } \\
\text { AFB1 (ppm) }\end{array}$ & $\begin{array}{c}\text { Fraction II level of } \\
\text { AFB1 (ppm) }\end{array}$ \\
\hline REF3 a & - & - \\
REF3 b & - & - \\
REF3 c & - & - \\
REF3 d & - & - \\
\hline
\end{tabular}

Table 4. Quantification of AFB1 content of commercial vegetable oils by TLC.

\begin{tabular}{lccc}
\hline $\begin{array}{c}\text { Sample } \\
\text { name }\end{array}$ & $\begin{array}{c}\text { Fraction I } \\
\text { level of } \\
\text { AFB1 (ppm) }\end{array}$ & $\begin{array}{c}\text { Fraction II } \\
\text { level of AFB1 } \\
\text { (ppm) }\end{array}$ & $\begin{array}{c}\text { Fraction III } \\
\text { level of } \\
\text { AFB1 (ppm) }\end{array}$ \\
\hline Gold winner & - & - & - \\
Saffola & - & - & - \\
Sundrop & - & - & - \\
Gemini & 0.24 & 0.16 & - \\
S.V.S. & 0.224 & 0.36 & - \\
Sunland & 0.24 & 0.208 & - \\
V.V.S. & 0.24 & 0.3 & - \\
Idaiyam & 0.224 & 0.264 & - \\
Anandam & - & - & - \\
Ruchi & 0.24 & 0.496 & - \\
Peanut oil 1 & 0.16 & 0.08 & - \\
Peanut oil 2 & 0.504 & 0.224 & - \\
Peanut oil 3 & 0.24 & 0.224 & - \\
\hline
\end{tabular}




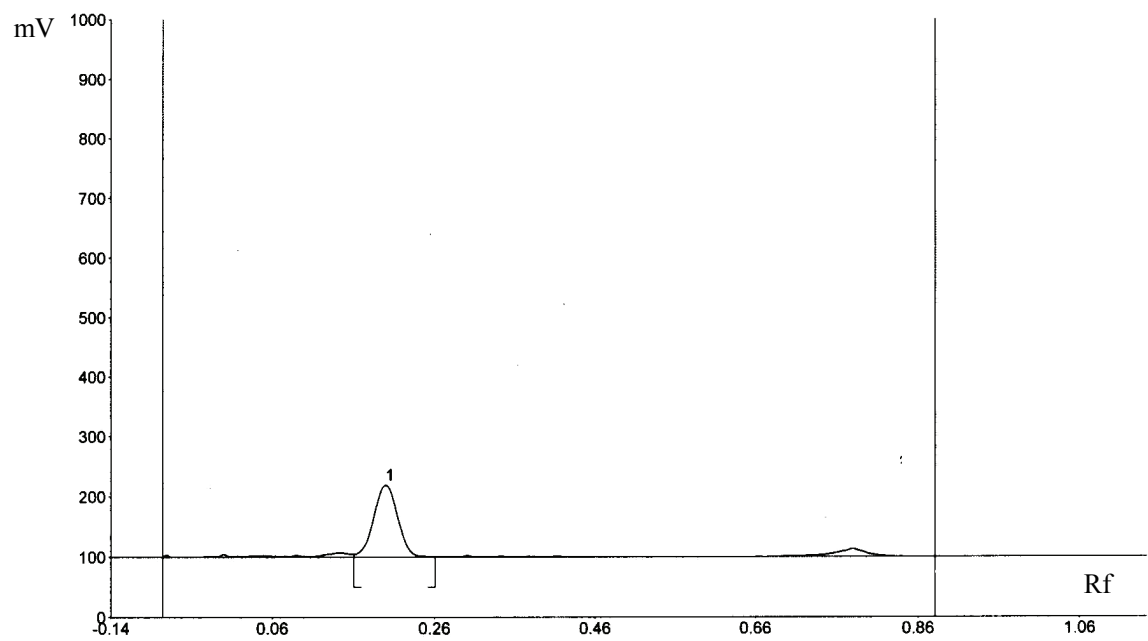

Figure 1. Authentic aflatoxin B1.

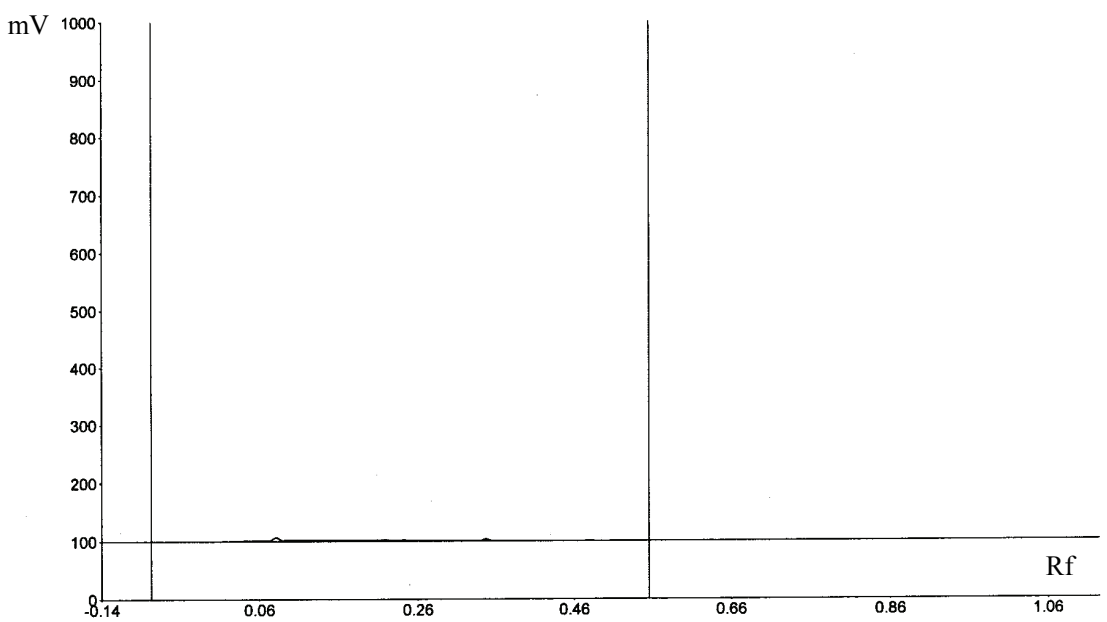

Figure 2. First fraction of REF3 a.

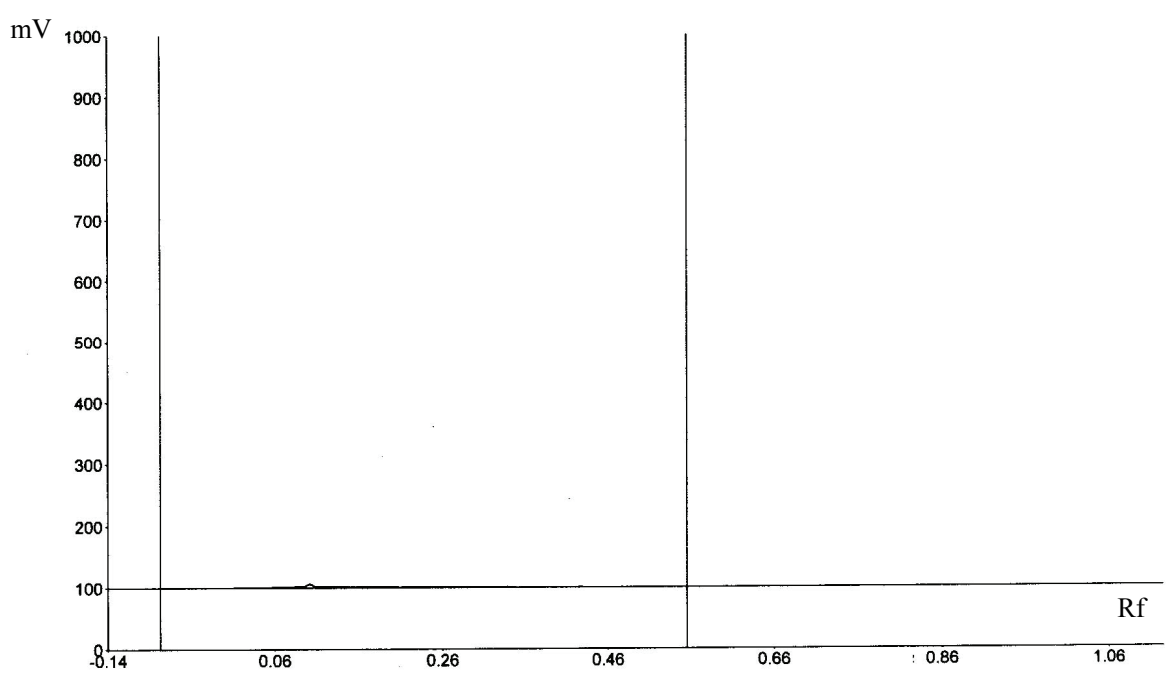

Figure 3. Second fraction of REF3 a. 


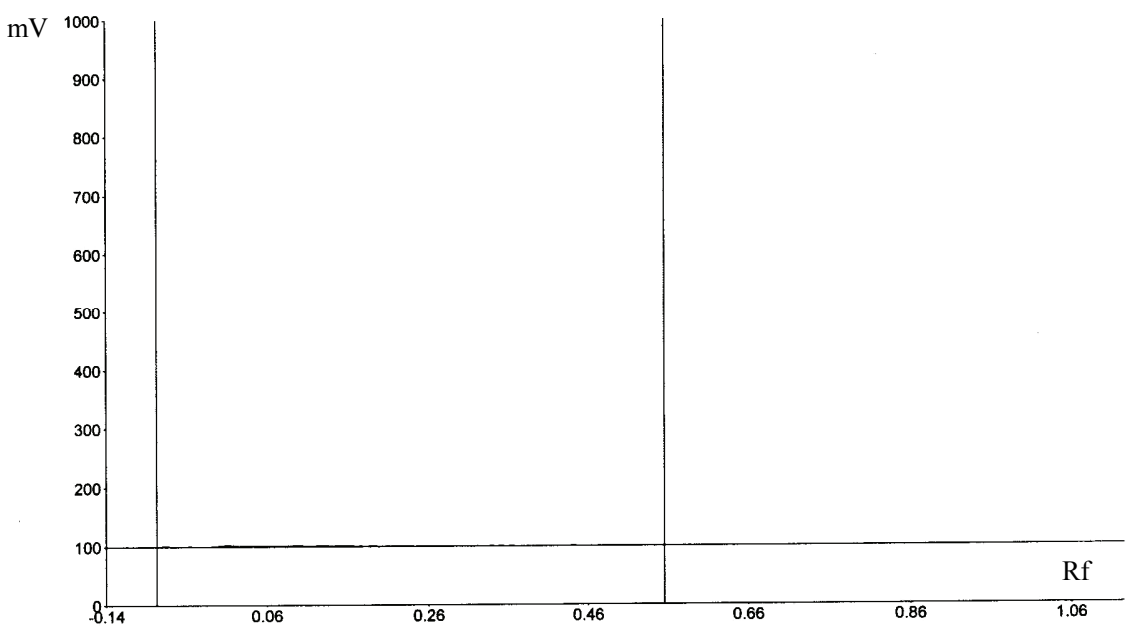

Figure 4. First fraction of REF3 $b$.

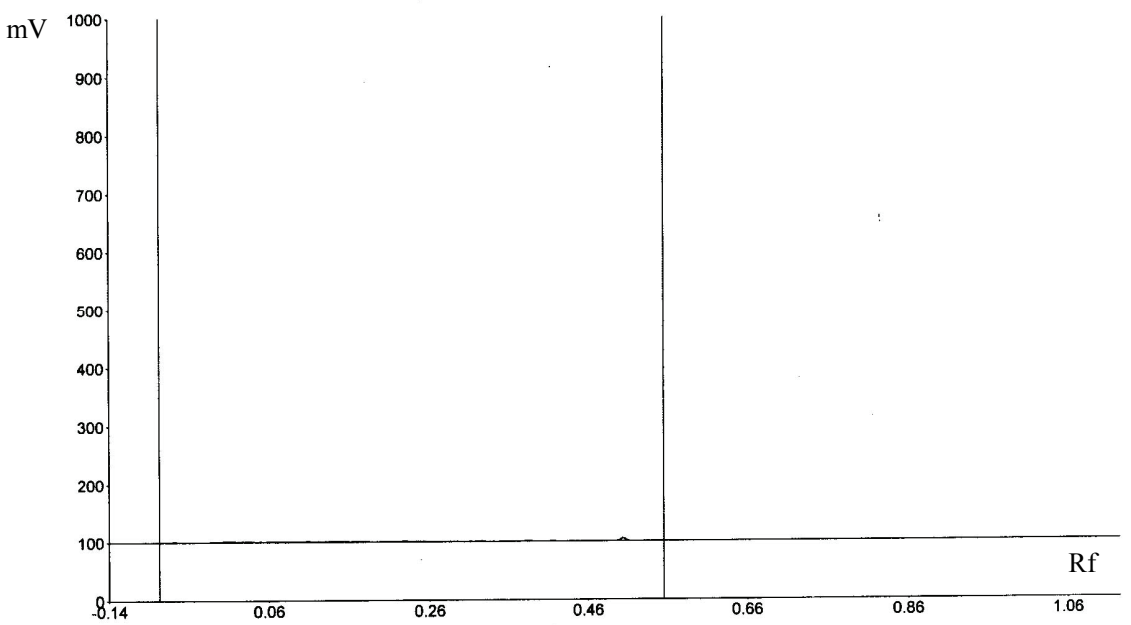

Figure 5. Second fraction of REF3 b.

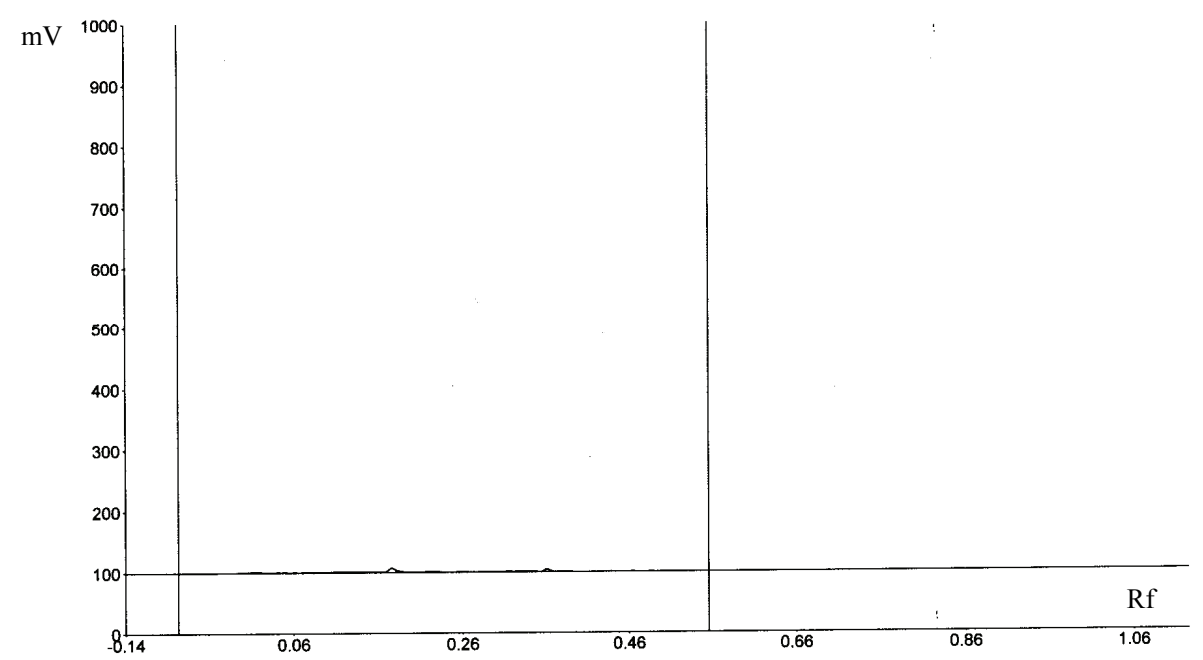

Figure 6. First fraction of REF3 c. 


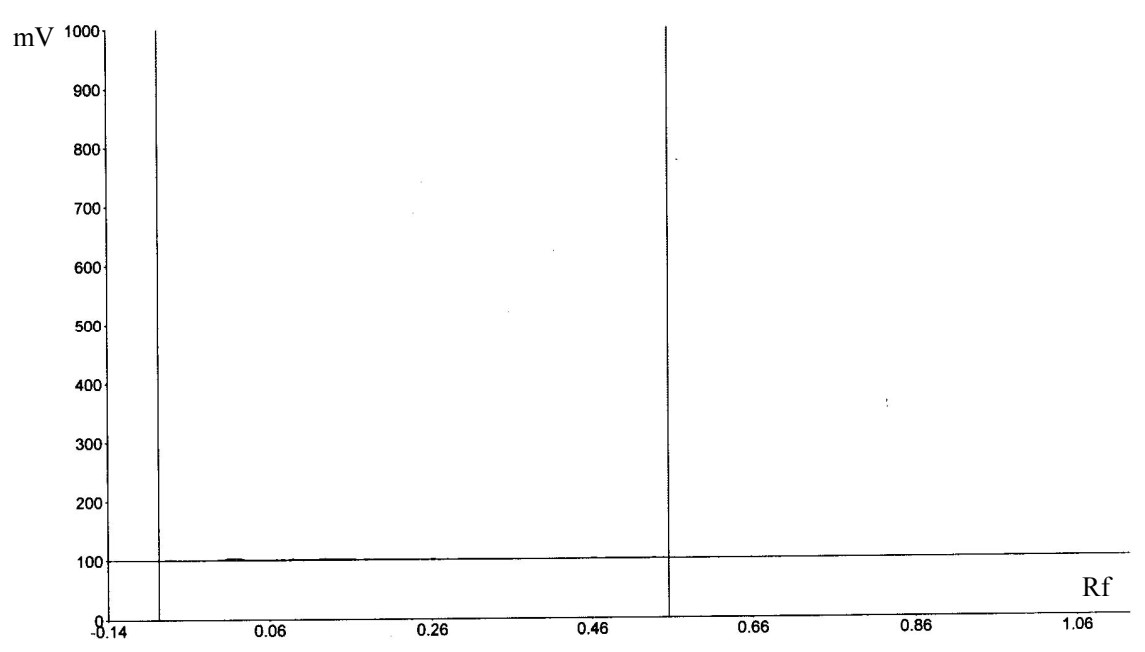

Figure 7. Second fraction of REF3 c.

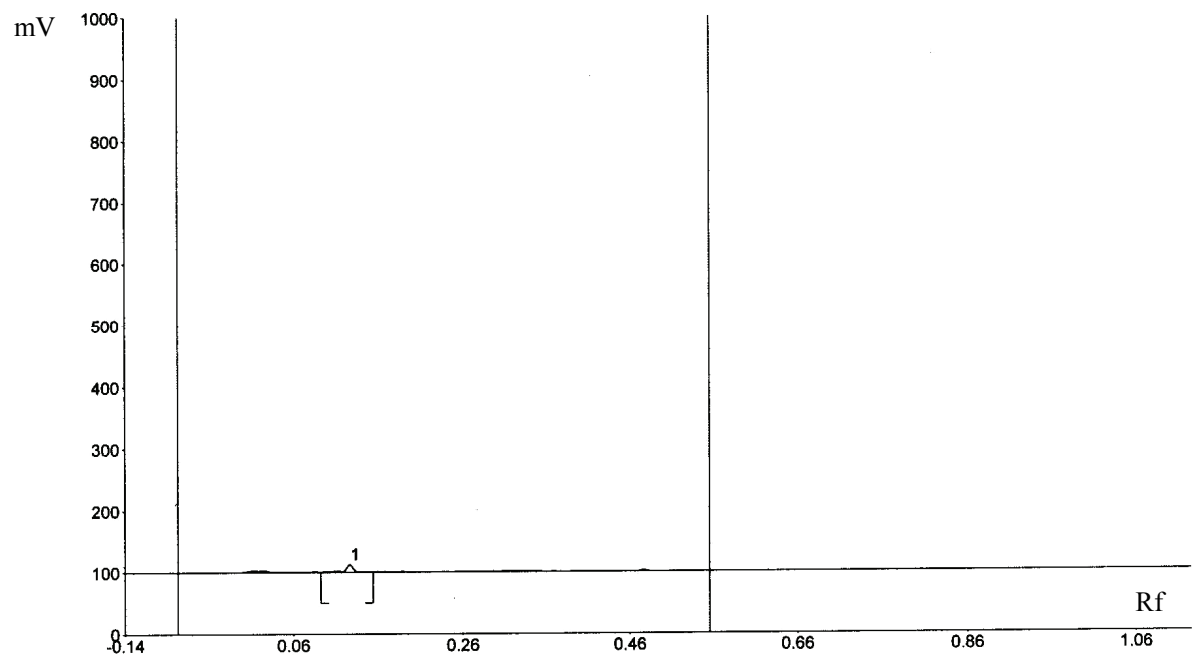

Figure 8. First fraction of REF3 d.

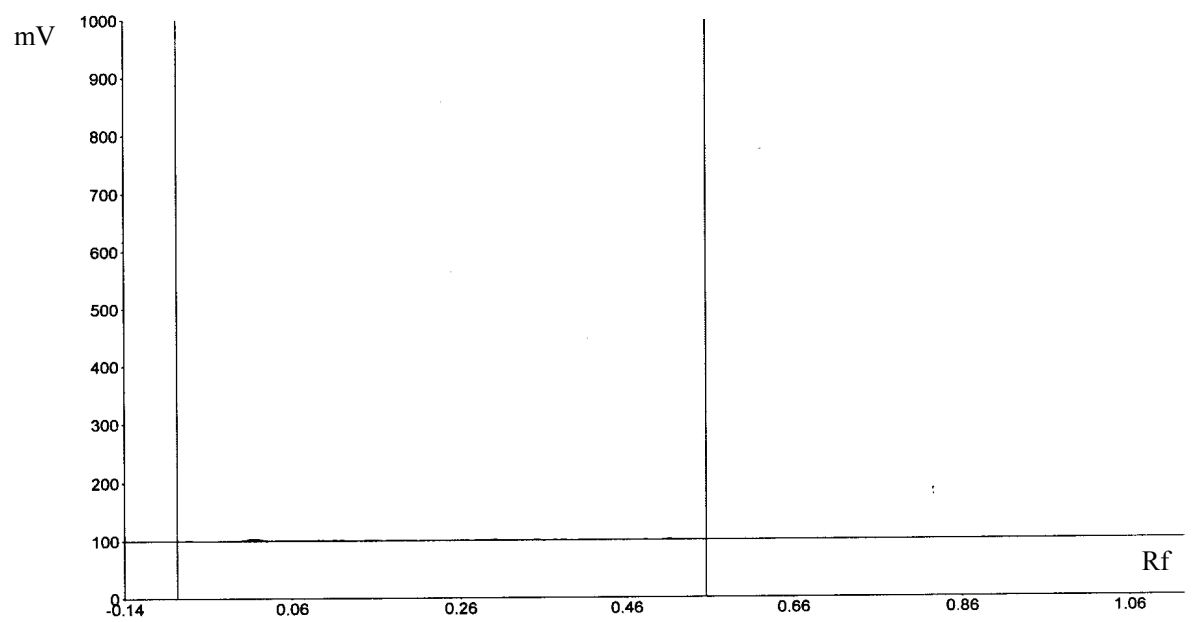

Figure 9. Second fraction of REF3 d. 


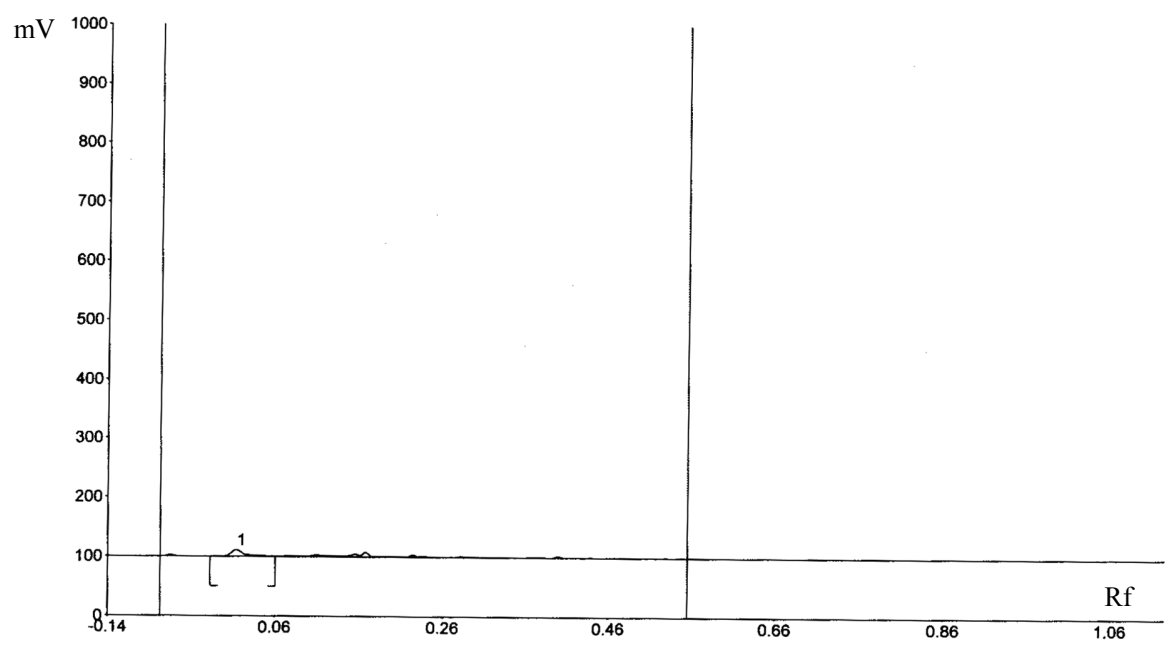

Figure 10. First fraction of gold winner sunflower oil.

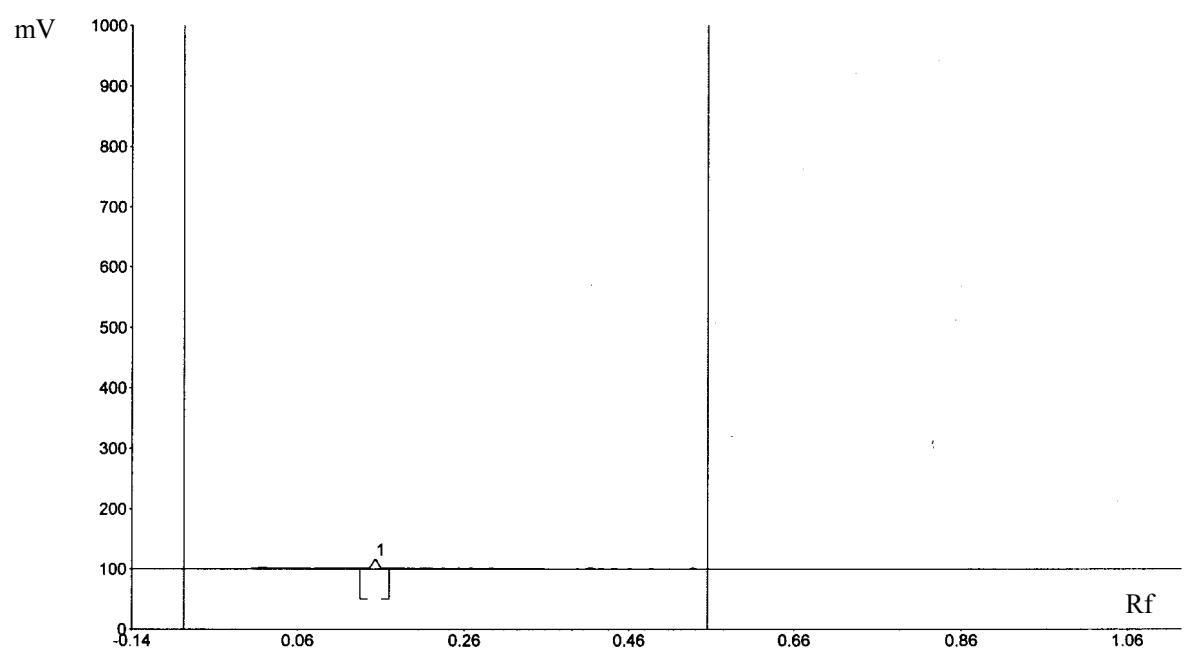

Figure 11. Second fraction of gold winner sunflower oil.

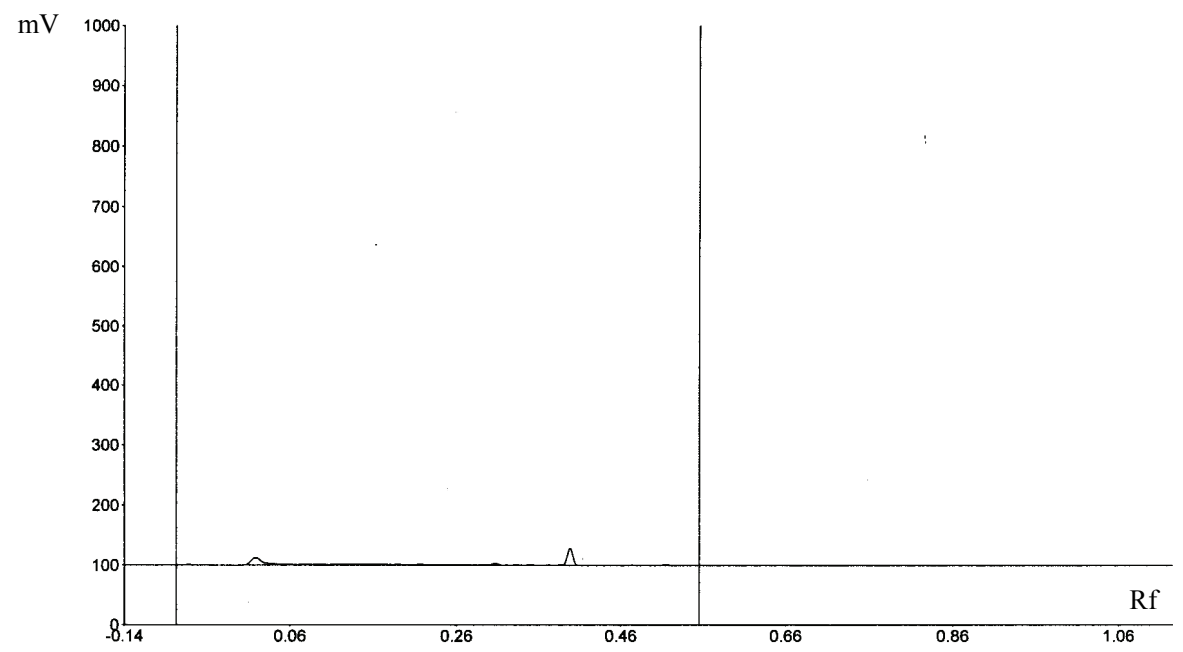

Figure 12. First fraction of saffola sunflower oil. 
$\mathrm{mV}$

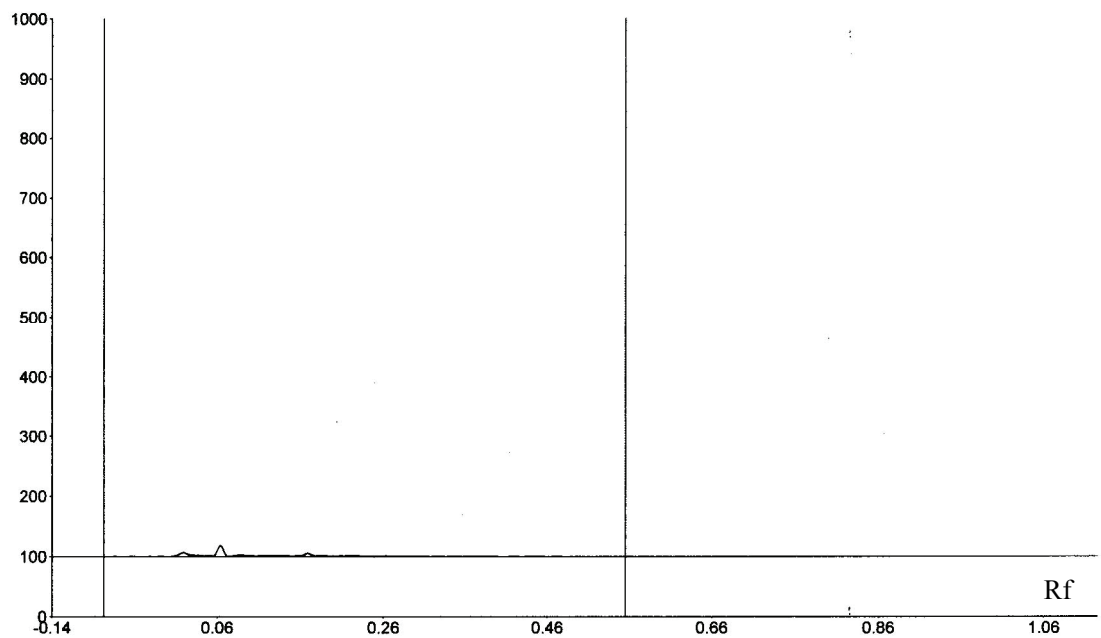

Figure 13. Second fraction of saffola sunflower oil.

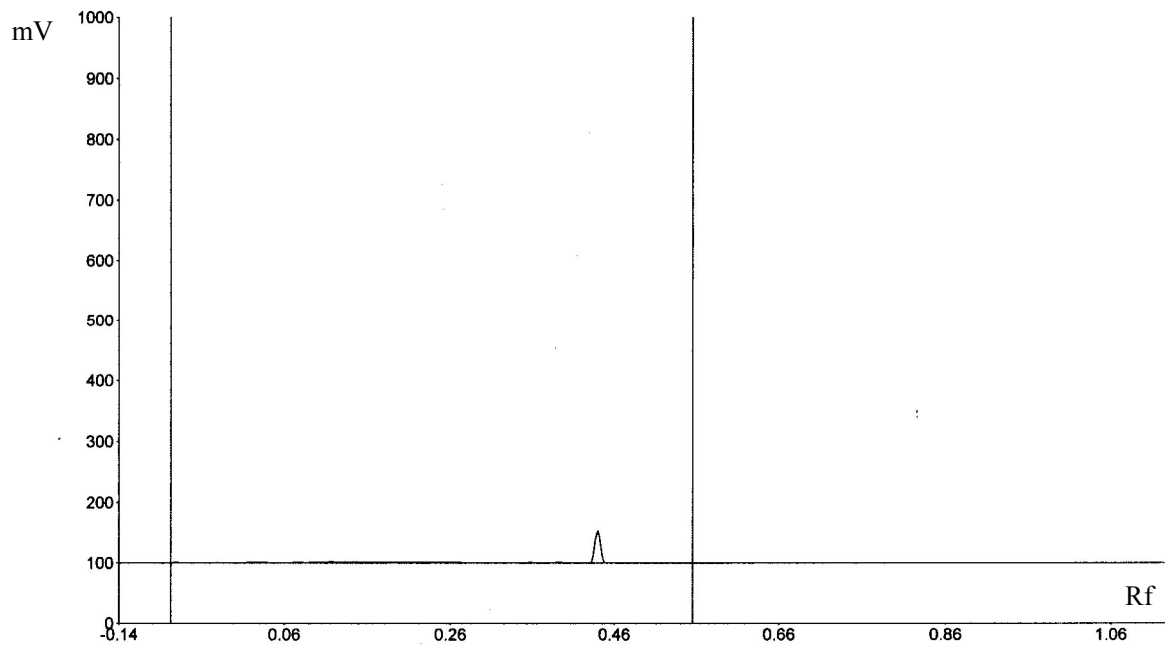

Figure 14. First fraction of sundrop sunflower oil.

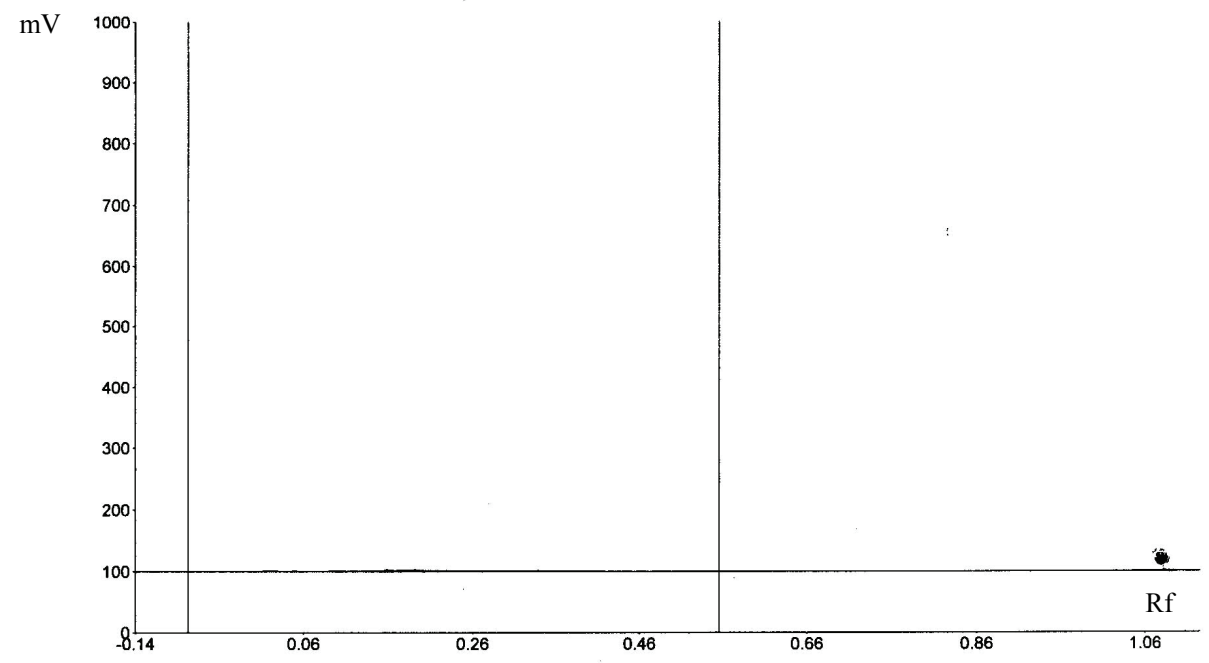

Figure 15. Second fraction of sundrop sunflower oil. 


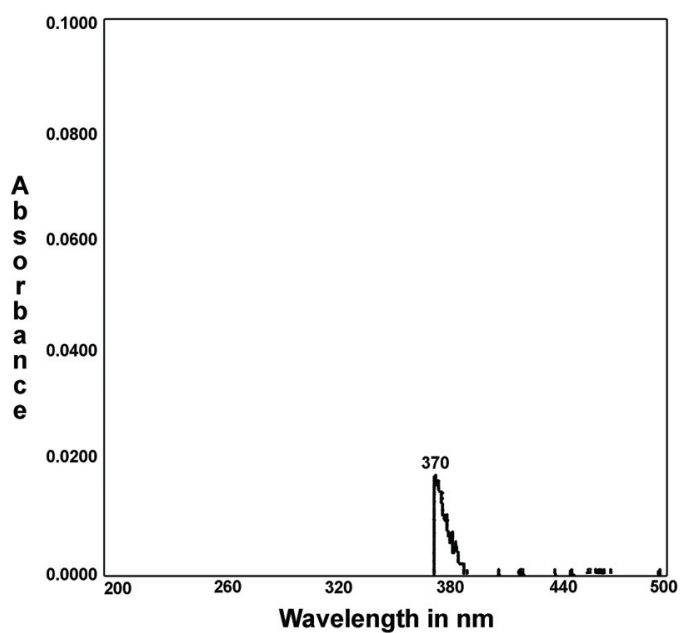

UV-Spectroscopic Analysis

Figure 16. Authentic aflatoxin B1.

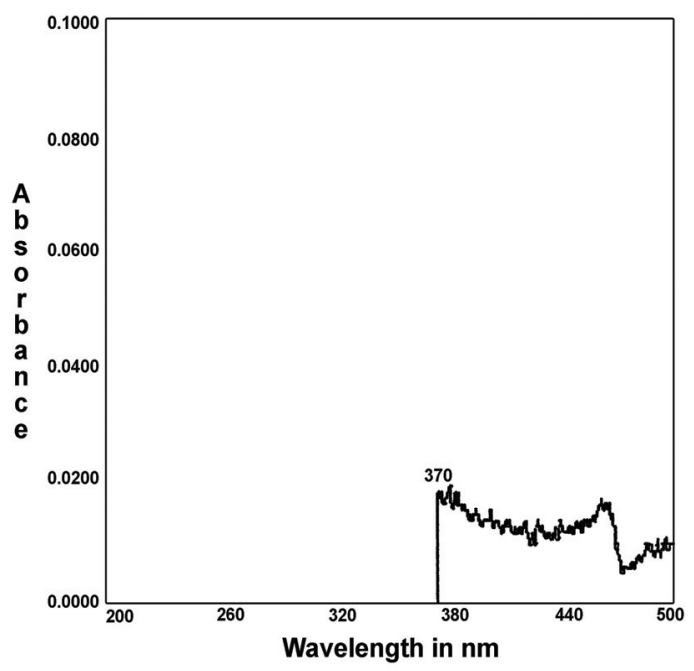

Figure 17. UV spectrum of second fraction of RO1 b.

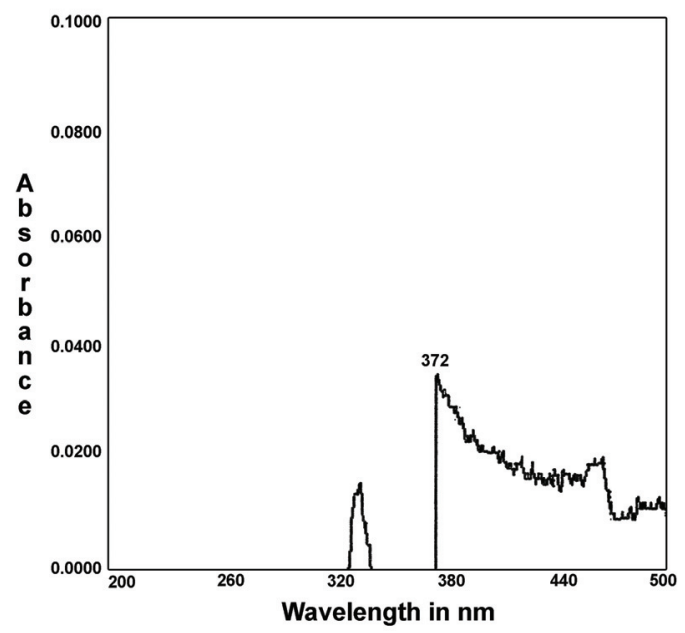

Figure 18. UV spectrum of second fraction of FO1 b.

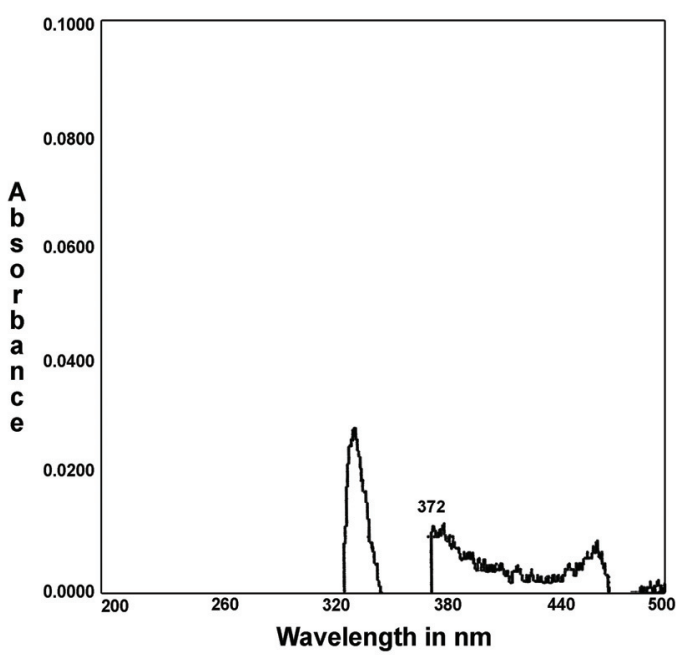

Figure 19. UV spectrum of second fraction of $\mathrm{RO} 2 \mathrm{~b}$.

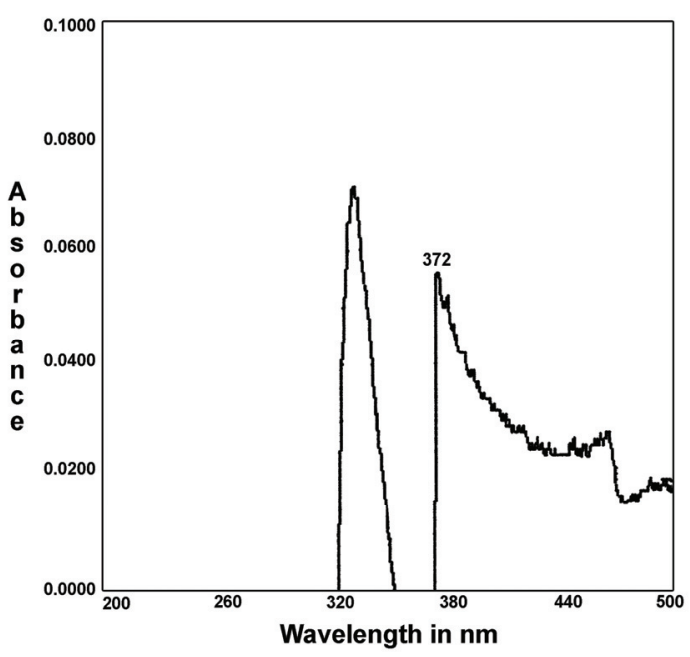

Figure 20. UV spectrum of first fraction of FO2 b.

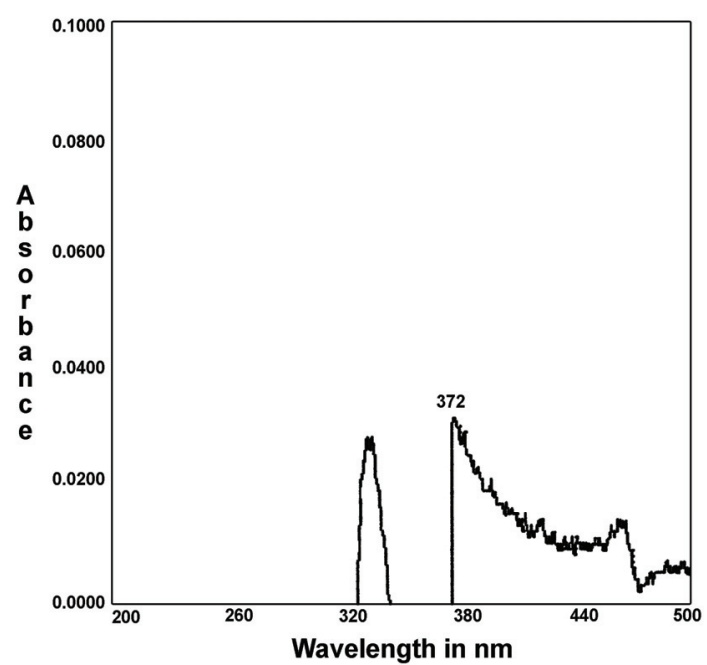

Figure 21. UV spectrum of first fraction of RO3 b. 


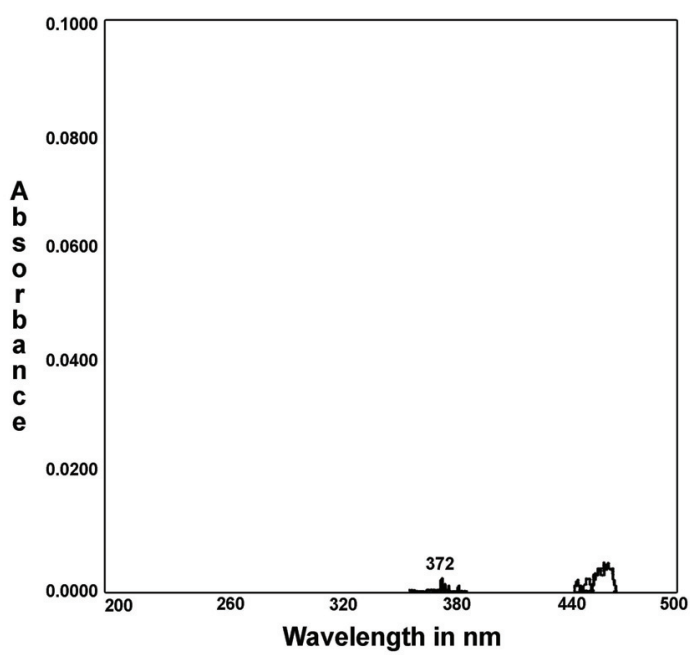

Figure 22. UV spectrum of first fraction of RO1 $\mathrm{c}$.

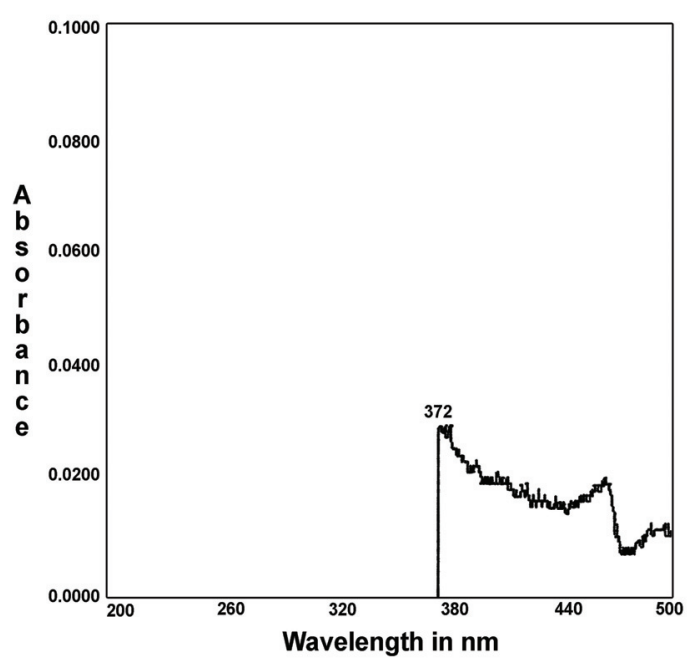

Figure 23. UV spectrum of second fraction of FO1 c.

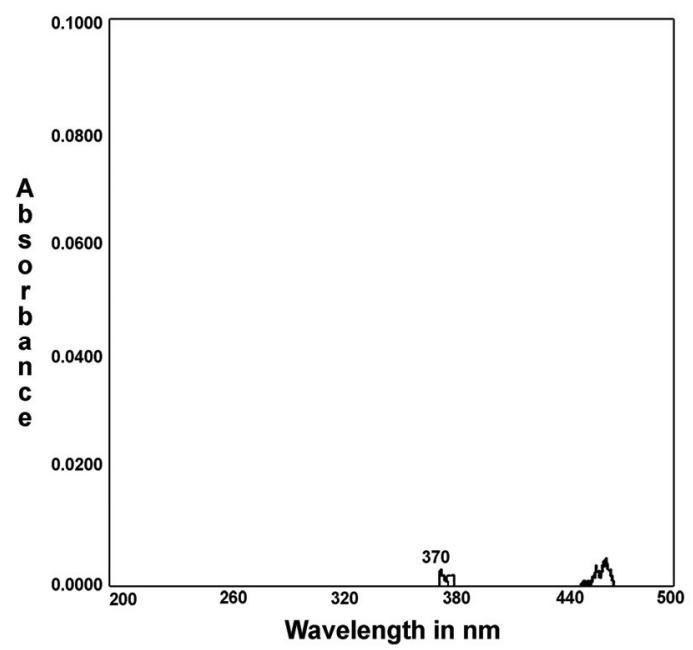

Figure 24. UV spectrum of second fraction of $\mathrm{RO} 2 \mathrm{c}$.

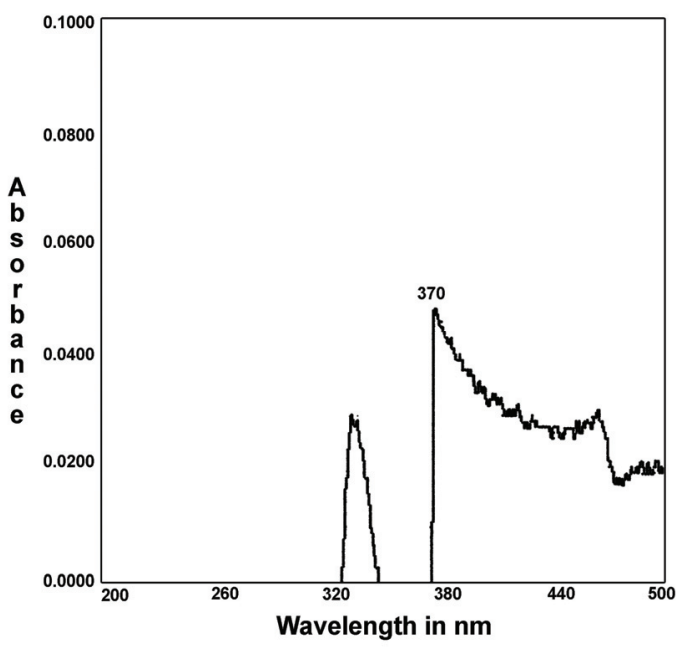

Figure 25. UV spectrum of second fraction of RO1 d.

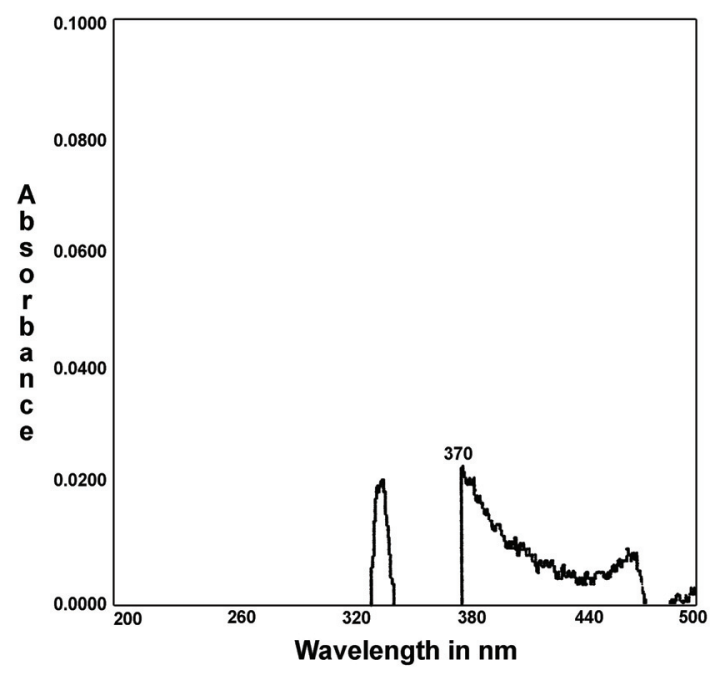

Figure 26. UV spectrum of second fraction of FO1 d.

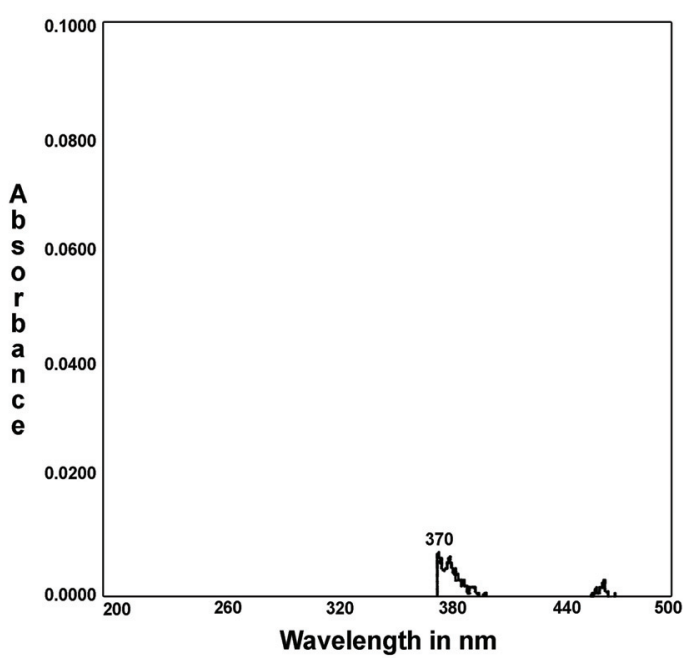

Figure 27. UV spectrum of first fraction of $\mathrm{FO} 2 \mathrm{~d}$. 


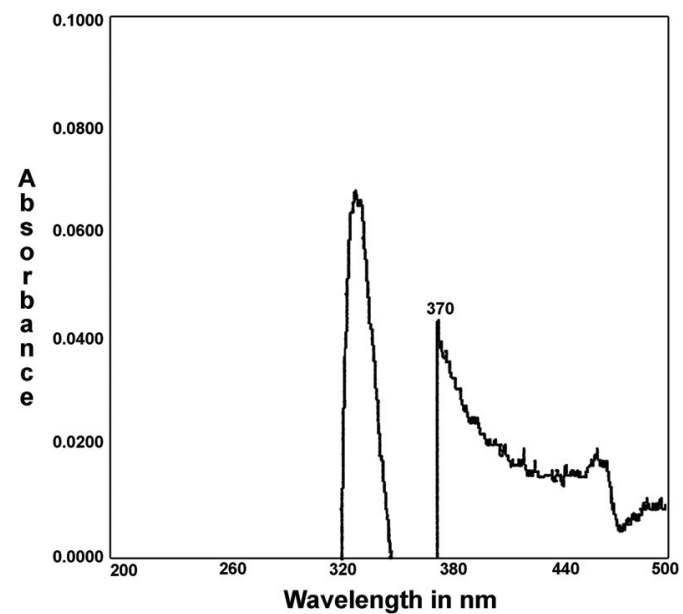

Figure 28. UV spectrum of first fraction of $\mathrm{RO} 2 \mathrm{~b}$.

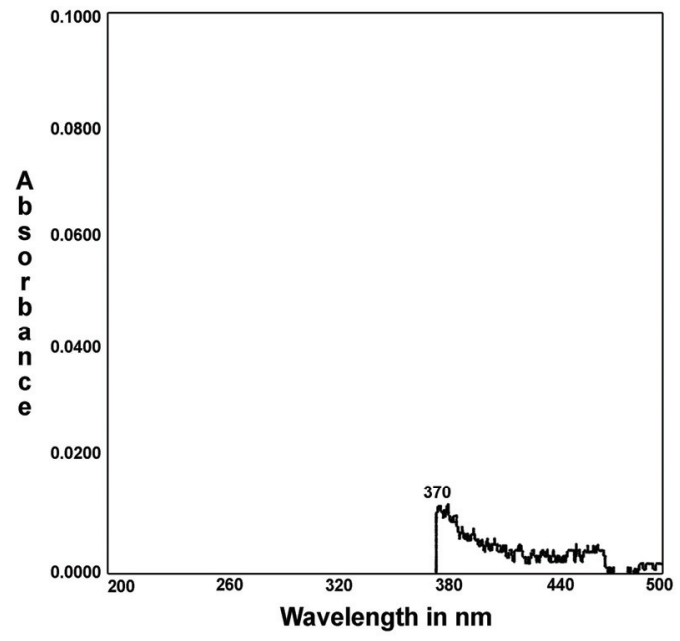

Figure 29. UV spectrum of first fraction of V.V.S. sunflower oil.

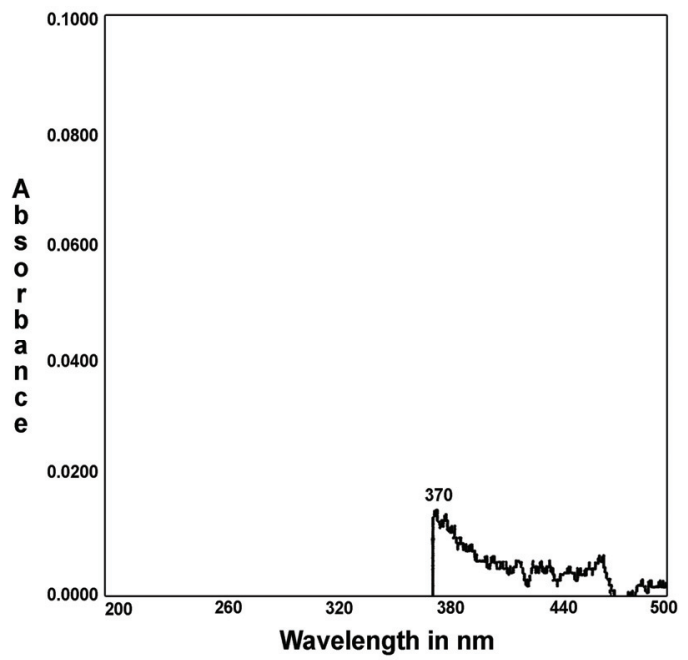

Figure 30. UV spectrum of first fraction of S.V.S. sunflower oil.

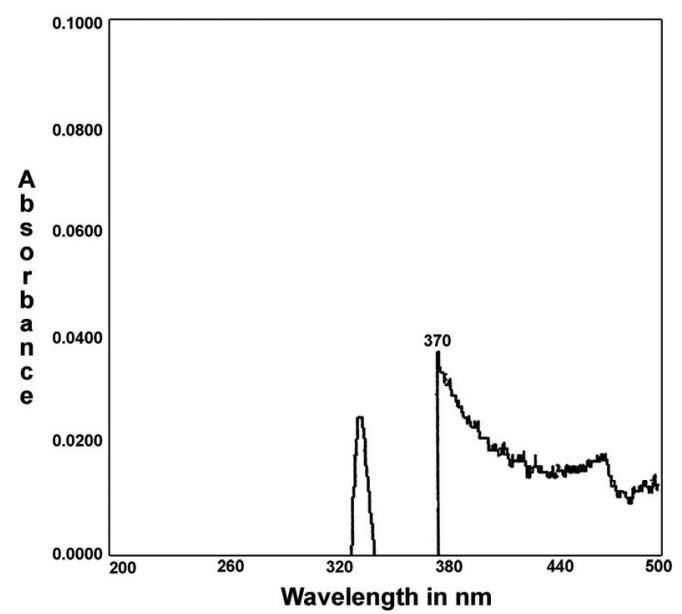

Figure 31. UV spectrum of second fraction of sunland sunflower oil.

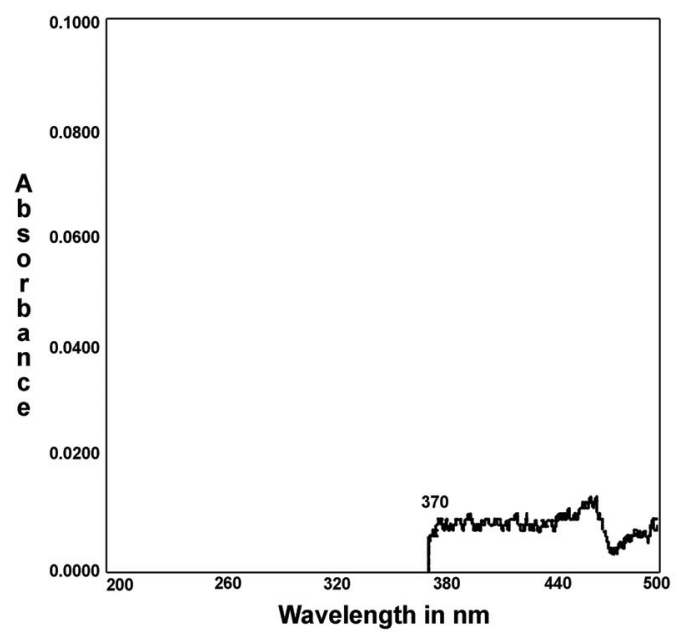

Figure 32. UV spectrum of first fraction of ruchi palm oil.

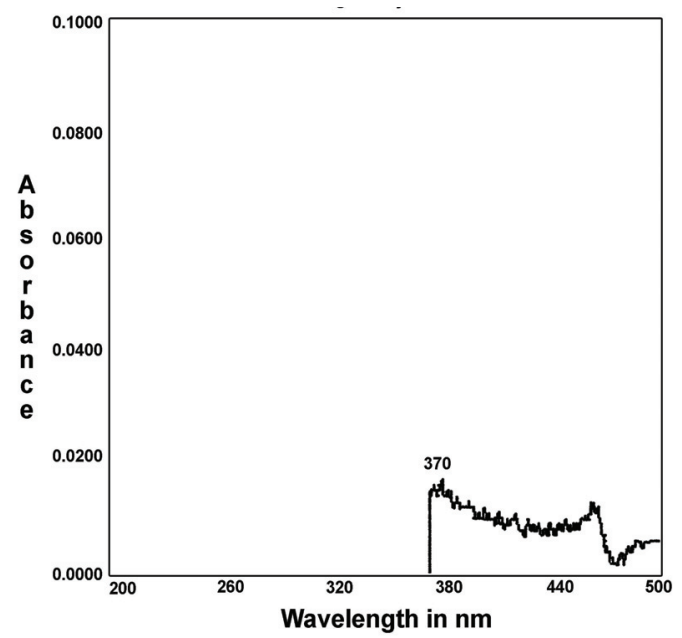

Figure 33. UV spectrum of second fraction of idaiyam gingelly oil. 


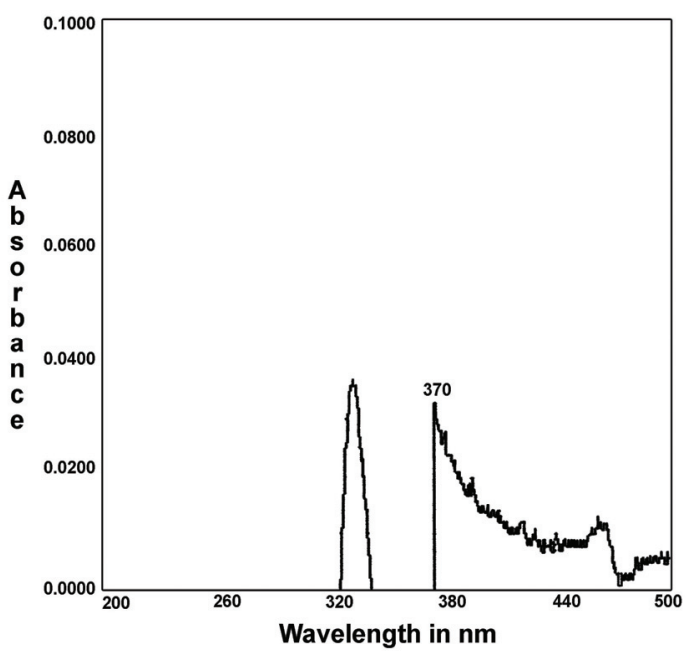

Figure 34. UV spectrum of first fraction of gemini sunflower oil.

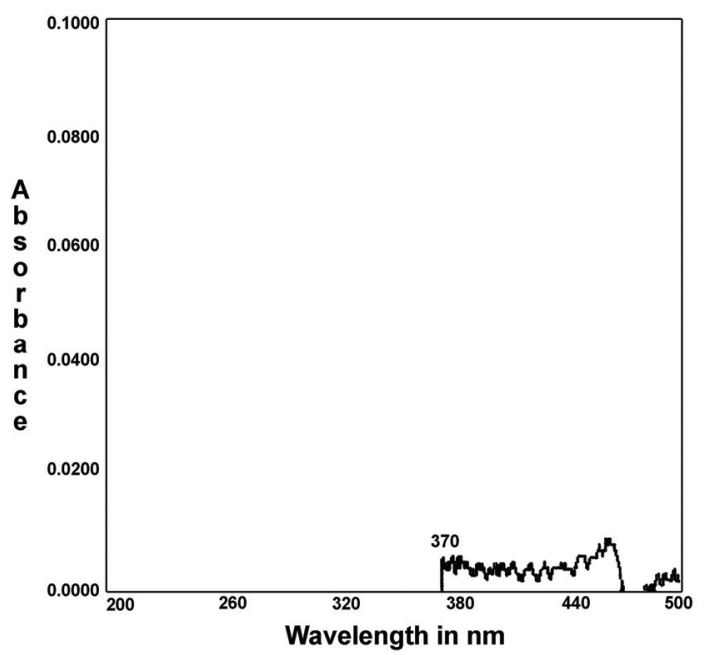

Figure 35 UV spectrum of first fraction of peanut oil 1.

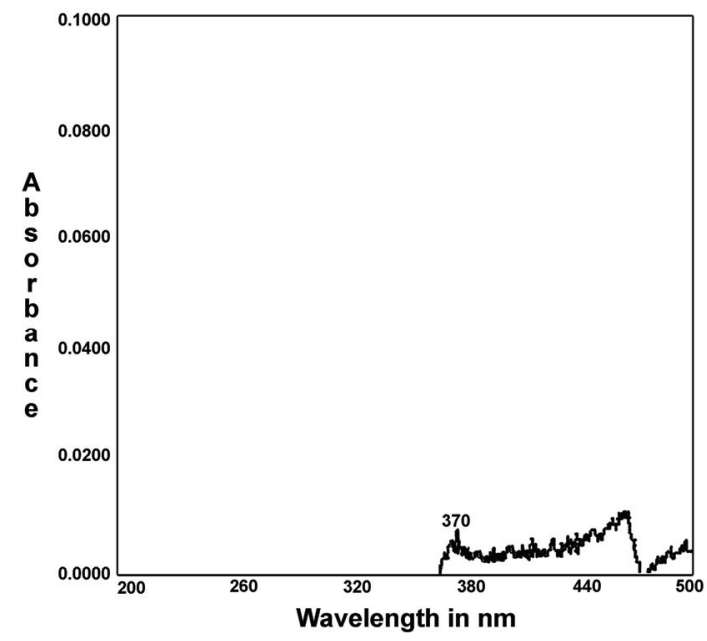

Figure 36. UV spectrum of first fraction of peanut oil 2.

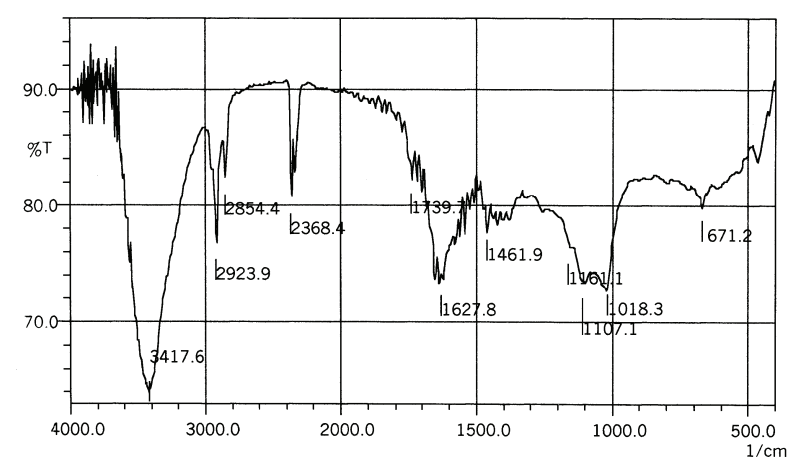

Figure 37. FTIR of authentic aflatoxin B1.

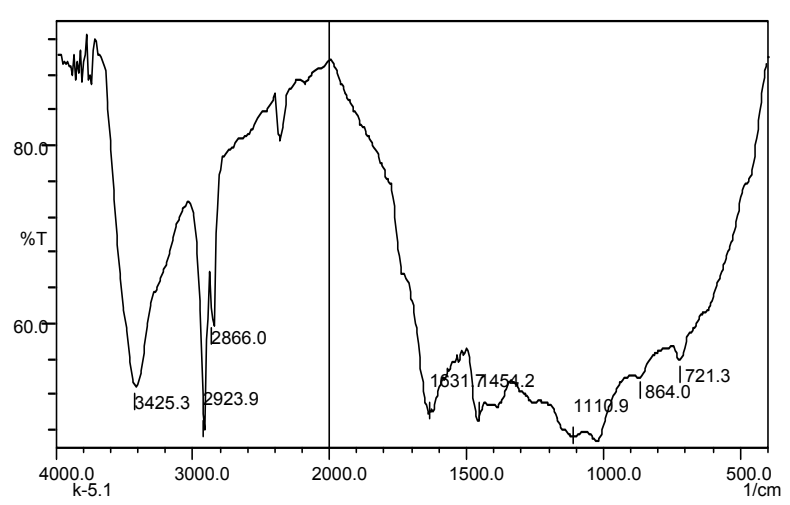

Figure 38. FTIR of first fraction of RO $3 \mathrm{a}$.

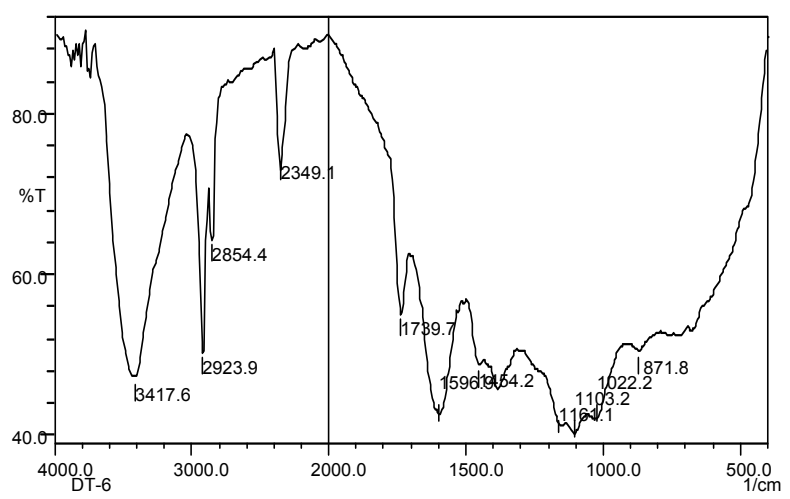

Figure 39. FTIR of first fraction of REF $3 a$.

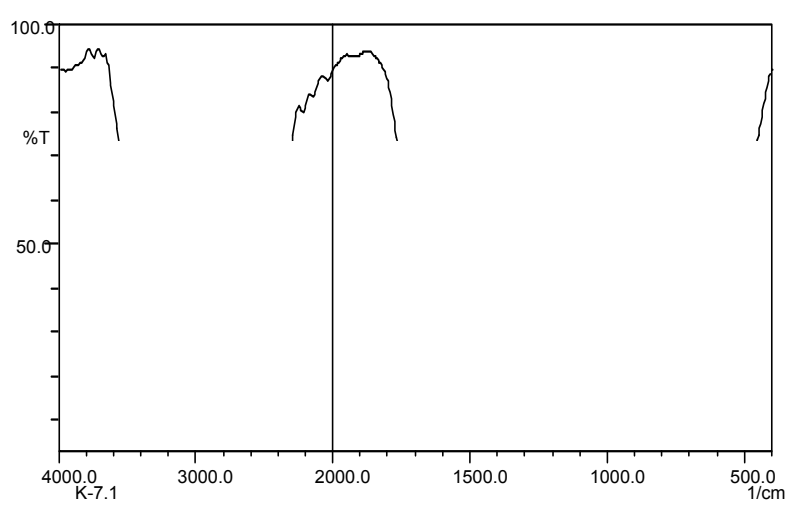

Figure 40. FTIR of first fraction of RO $1 \mathrm{~b}$. 


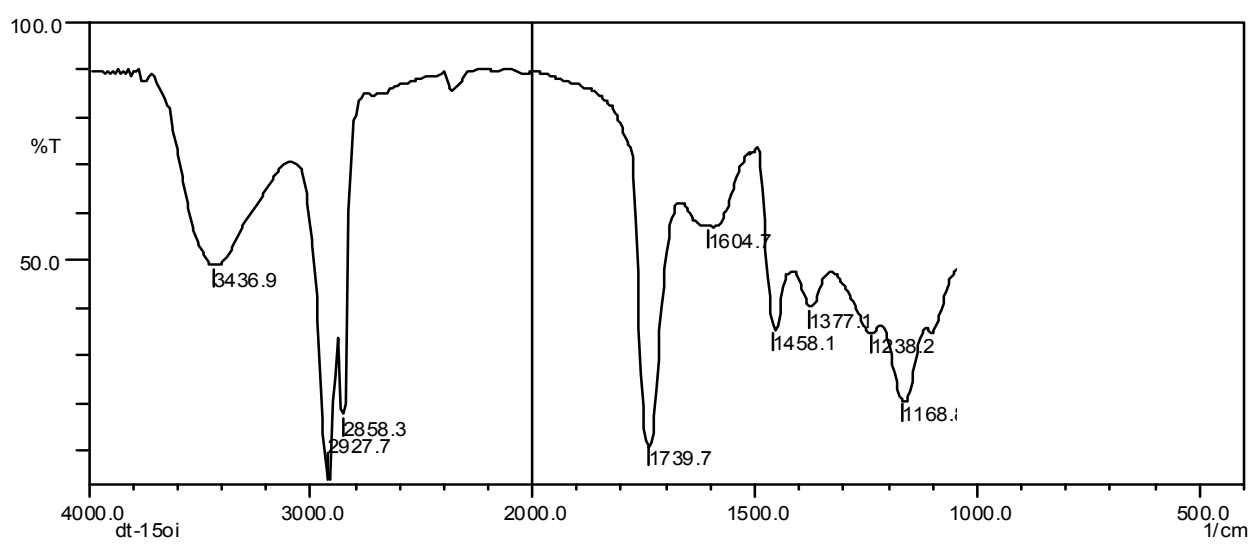

Figure 41. FTIR of first fraction of RO 2c.

was not eluted in fraction three. It was eluted only in both first and second fractions.

The AFB1 contamination of peanut oil was highest (0.504 ppm) followed by ruchi palm oil (0.496 ppm), S.V.S. sunflower oil $(0.36 \mathrm{ppm})$ and V.V.S. gingelly oil $(0.3 \mathrm{ppm})$. Both the fractions of sunflower oils namely, gold winner, saffola and sundrop showed no contamination of AFB1 analysed by HPTLC.

The evidence seems unequivocal that conventional processing practices remove essentially completely any aflatoxin that may be found in raw sunflower oils. If properly stored, vegetable oil has a shelf-life ranging from 6-12 months. Heat applied during processing destroys enzymes in raw materials, and also any contaminating microorganisms which would cause rancidity. Additionally, the oil may be heated after extraction to remove as much water as possible, this lessens the occurrence of microbial spoilage during storage. Correct packaging and storage conditions slow down chemical changes caused by light and heat which may lead to rancidity [11]. During storage of raw sunflower oil in different packaging materials and heat treatment affected the colour, odour, free fatty acid and iodine value of oil. The airtight high density polyethylene (HDPE) pouches (120 gauge) with heat-treated oil were found to be the best packaging materials for storage of oil up to a period of 16 weeks [12].

\section{CONCLUSIONS}

In the present study, the level of AFB1 contamination in all the vegetable oils tested showed very least amount of contamination and their level was permissible according to FDA. So this adds advantages to the vegetable oil refineries and to the consumers. But this low level may be biomagnified in our body leading to Hepato Cellular Carcinoma (HCC). So, we have to look for new methods of detoxification and decontamination of A. flavus and its toxins.

The research is essential to respond to the needs of our country in confronting the mycotoxin problem. The research undertaken reflects the current status in the development of mycotoxin problem. The work should be recognized by the industries for transferring the results into practical applications.

\section{ACKNOWLEDGEMENTS}

We sincerely thank the Department of Science and Technology, Government of India, for funding this project.

\section{REFERENCES}

[1] Davie, J. and Vincent, L. (1980) Extraction of vegetable oil and fats. In: Hamilton, R.J. and Bhati, A., Eds., Fats and oils: Chemistry and technology, Applied Science Publishers, London, 123-164.

[2] Chong, Y.H. and Beng, C.G. (1965) Aflatoxins in unrefined groundnut oils. Medical Journal of Malaya, 20(1), 49-50.

[3] Chong, Y.H. (1966) Aflatoxins in groundnuts and groundnut products. Far East Medical Journal, 2, 228230.

[4] Dwaraknath, C.T., Sreenivasamurthy, V., and Parpia, H.A.B. (1969) Aflatoxins in Indian peanut oil. Journal of Food Science and Technology, 6, 1.

[5] Basappa, S.C. and Sreenivasamurthy, V. (1977) State of aflatoxin in groundnut oil. Journal of Food Science and Technology, 14, 57-60.

[6] Basappa, S.C. and Sreenivasamurthy, V. (1979) Decontamination of groundnut oil from aflatoxin. Indian Journal of Technology, 17, 440.

[7] Bassappa, S.C. (1983) In: Bilgrami, K.S., Prasad, T. and Sinha, K.K., Eds., Mycotoxins in food and feeds. The Allied Press, Bhagalpur, 251-275.

[8] Tulpule, P.G., Nagarajan, V. and Bhat, R.V. (1982) Environmental India Review - Series 1, Department of Environment, Government of India, New Delhi.

[9] Miller, N., Pretorius, H.E. and Trinder, D.W. (1985) De- 
termination of aflatoxins in vegetable oils. Journal of Association of Analytical Chemistry, 68(1), 136-137.

[10] Kamimura, H, Nishijima, M, Tabata, S, Yasuda, K, Ushiyama, H. and Nishima, J. (1986) Survey of mycotoxin contamination in edible oil and fate of mycotoxins during oil refining processes. Journal of Food Hygienic Society of Japan, 27(1), 59-63.

[11] Vijayalakshmi, M. and Rao, A.S. (1993) Effect of seed-borne fungi and quality of sunflower (Helianthus annuns) oil. Indian Journal of Agricultural Science, 63,
529-531.

[12] Raghav, P.K, Grover, P.C. and Thapar, V.K. (1999) Storage stability of Sunflower (Helianthus annus) oil in different packaging materials. Journal of Food Science and Technology, 36, 253-255.

[13] Banu, N. (2004) Studies on mycobiota from sunflower oil refineries with reference to mycotoxins from the fungi and the feed and oil samples. Ph.D. Thesis, University of Madras, Chennai. 